\title{
BUSINESS REPORTS
}

\section{Atla Association Update}

Brenda Bailey-Hainer, Atla Executive Director

\begin{abstract}
The Atla Association Update provides highlights of Atla's accomplishments for the year, an overview of finances for fiscal year 2020, and a brief preview of the projected budget for fiscal year 2021.
\end{abstract}

Each year at Atla Annual, I provide an update on the finances and accomplishments of Atla during the previous year along with a look at high priorities for the next year. Due to the condensed nature of Atla Annual 2020 Online, my usual update on the Association has been combined with the official business meeting. Because of this, my remarks will be relatively brief and primarily about the Association's financial health, but a detailed report, including information on Atla's many accomplishments since last year, will be included in the July 2020 Atla Newsletter.

Last fiscal year, which ended August 31, 2019, was a financially healthy one for Atla. As always, our budget for the year was breakeven, with $\$ 7,966,799$ projected for both revenue and expense. Although at the end of the year our revenue came in slightly less at $\$ 7,477,770$, our expenses also were less than anticipated at $\$ 7,368,768$.

Atla's primary source of revenue continued to be royalties from the research tools we create (93\%). Income generated from Member Programs department activities was related to the conference and fees for services such as hosting e-journals for other organizations (4\%). Interest from investments and other miscellaneous income accounted for another $3 \%$ of overall revenue. 
On the expense side, the largest portion is used for staff and technology to produce research tools (61\%). However, we focus a significant amount of income on fulfillment of our mission and organizational ends-last year this was $23 \%$. That includes funding committee work, open access publishing, Member Programs staff, and professional development opportunities for our members-like Atla Annual. Board meetings and other governance work makes up $4 \%$ of expenses and administration costs comprise $12 \%$.

Because fiscal year 2019 was a successful one, at the end of last year we were able to invest in Atla's future. \$50,000 was contributed to the Endowment Fund from product revenue. As of midJune, the current balance in the Endowment Fund was $\$ 785,708$, an increase of over $\$ 100,000$ from the previous year. In addition, we were able to add $\$ 100,000$ to our operating reserve. The operating reserve is a fund mandated by the Board of Directors to cover unforeseen expenses or unexpected capital expenditures. The operating reserve must be maintained at a level between three to six months of monthly operating cost. For fiscal year 2020, it stands at $\$ 2.3$ million, equal to 4.75 months of operating cost. Atla's audited fiscal year 2019 financial statements are available online in the Annual Report.

Our membership numbers have been fairly consistent over the last seven years, holding steady in the low to mid-800s. Memberships at the end of fiscal year 2019 stood at 830.

Currently, we are about three-quarters of the way through fiscal year 2020 . This year's budget is $\$ 8,516,285$. At this point in the year, we are on track to meet our revenue goals and our expenses are down significantly due to the impact of COVID-19, which has curtailed all travel and exhibiting expenses that we would normally have in the second half of the year.

The staff leadership team is in the middle of our regular budgeting cycle, which begins in March and ends with finalizing the budget in August. We are carefully watching the impact of COVID-19 on higher education because academic libraries are the primary market for our research tools. Like many of our member institutions, we expect reduced revenue next fiscal year-perhaps at a level closer to fiscal year 2018 or 2019. However, we are confident that we can live within our means. Just a few areas that we believe will have reduced expense in the coming year are travel-which we are curtailing through the end of the fiscal year due to health and safety reasonsand our expense for physical office space. The 15-year lease on our 
office space ends in February 2021, and we know that we will be significantly reducing our square footage in a new location. Another area in which we expect lower costs next year is infrastructure. Over the last seven years staff have been systematically updating various parts of our infrastructure-our production platform for the research tools, association management software, content management software, website design, and, finally, our accounting and budgeting systems. We will complete the last project in the next few months and there are no more major investments needed in infrastructure at this time.

So, let's turn to where we will focus our attention next year. The Atla Board of Directors adopted new organizational ends in February. A new strategic plan is being developed and workplans for committees and task forces will be created specifically to work on achieving those ends. Staff will be completing a search for new office space in the next few months, and then we'll focus on successfully exiting our current space. But most importantly, we will continue to focus both human and financial resources on creating quality professional development opportunities for members, and we will continue to create the quality research tools that support your work with your faculty and students.

But we are concerned about the well-being of our members. While we feel confident that Atla itself can weather the turmoil that COVID-19 has caused, we know that the pandemic is having a significant impact on many Atla members. This has manifested itself in budget cuts, layoffs, furloughs, or eliminated positions. We were pleased to be able to offer free event registration for members to attend Atla Annual 2020 Online but wanted to do more. At their regular meeting on June 16, the Atla Board of Directors authorized Atla to offer members financial relief through optional dues reduction for fiscal year 2021. At the point of renewal, individual members may pay their regular dues amount, or choose to take a discount of 25, 50, 75 , or $100 \%$. Institutional members may choose to pay their regular dues or take a discount of $25 \%$. These rates are also available to new members. This is Atla's way of helping our members through these trying times by ensuring they still have access to the full benefits of Atla membership.

It's already clear that the coming year will be fraught with challenges, but ample opportunities exist as well to make progress on moving forward with Atla's new organizational ends and our ongo- 
ing purpose: to promote worldwide scholarly communication in religion and theology by advancing the work of libraries and related information providers. Together, we can still thrive in the face of adversity. 